\title{
Corticosteroid-induced Kaposi's Sarcoma Revealed by Severe Anemia: A Case Report and Literature Review
}

\author{
Go Endo ${ }^{1}$ and Naoyoshi Nagata ${ }^{1,2}$
}

\begin{abstract}
:
We herein report a case of gastrointestinal (GI) Kaposi's sarcoma (KS) without cutaneous involvement in a 73-year-old man who had received immunosuppressive drugs for granulomatosis with polyangiitis. After one year of prednisolone use, he presented with tarry stool and severe anemia. Endoscopic and pathological examinations revealed bright-reddish protruding lesions with proliferating spindle cells positive for D2-40, CD34, and HHV-8, which are definitively diagnostic of GI-KS. Drug-induced KS without HIV infection or transplantation is extremely rare, and its clinical features remain unknown. Therefore, we conducted a literature review of steroid-induced KS.
\end{abstract}

Key words: Kaposi’s sarcoma, granulomatosis with polyangiitis, steroid, immunosuppression

(Intern Med 59: 625-631, 2020)

(DOI: 10.2169/internalmedicine.3394-19)

\section{Introduction}

Kaposi's sarcoma (KS) is an angioproliferative disorder, the onset of which requires infection with human herpes virus 8 (HHV-8) (1). There are four presentations in which KS occurs: 1) the classic form, which typically presents in elderly persons of Mediterranean or Eastern European descent; 2) the endemic form, which has been described in indigenous peoples of Sub-Saharan Africa; 3) the iatrogenic form, which is associated with immunosuppressive drug therapy; and 4) the AIDS-associated form (2). The most common presentation is the AIDS-associated form (3), and iatrogenic $\mathrm{KS}$ is relatively rare. Steroids are the most widely used form of immunosuppressive therapy, but the typical background, management, and prognosis of patients with steroid-induced KS remain unknown. Furthermore, the management of steroid-induced KS may differ from that of other types of KS.

We herein report a case of gastrointestinal (GI)-KS who had received long-term steroid therapy for granulomatosis with polyangiitis. We also conducted a literature review of steroid-induced KS.

\section{Case Report}

The patient, a 73-year-old Mongolian man, had been diagnosed with granulomatosis with polyangiitis 1 year earlier. His treatment regimen consisted of high-dose cyclophosphamide $1,000 \mathrm{mg} / \mathrm{month}$ and systemic corticosteroids, intravenous methylprednisolone pulse followed by oral prednisolone $50 \mathrm{mg} /$ day (Fig. 1). Remission was achieved, and cyclophosphamide was changed to azathioprine $50 \mathrm{mg} / \mathrm{day}$, with prednisolone slowly tapered to $12 \mathrm{mg}$ /day over 11 months (Fig. 1).

After 11 months of therapy, he was hospitalized for tarry stool. He had taken lansoprazole daily for 11 months and was not taking any nonsteroidal anti-inflammatory drugs (NSAIDs). On his initial presentation, his vital signs were stable, and gastrointestinal, cardiovascular, pulmonary, skin, and extremities examinations were normal. An HIV-RNA test, cytoplasmic-antineutrophil cytoplasmic antibody, and Helicobacter pylori antibody were negative. His hemoglobin concentration was $6.0 \mathrm{~g} / \mathrm{dL}$, so he received 6 units of red blood cell transfusion. The hemoglobin concentration then increased to $7.9 \mathrm{~g} / \mathrm{dL}$ the next day and showed gradual improvement (Fig. 1).

${ }^{1}$ Department of Gastroenterology and Hepatology, National Center for Global Health and Medicine, Japan and ${ }^{2}$ Endoscopy Center, Tokyo Medical University Hospital, Japan

Received: May 27, 2019; Accepted: September 18, 2019; Advance Publication by J-STAGE: November 8, 2019

Correspondence to Dr. Naoyoshi Nagata, nnagata-ncgm@yahoo.co.jp 


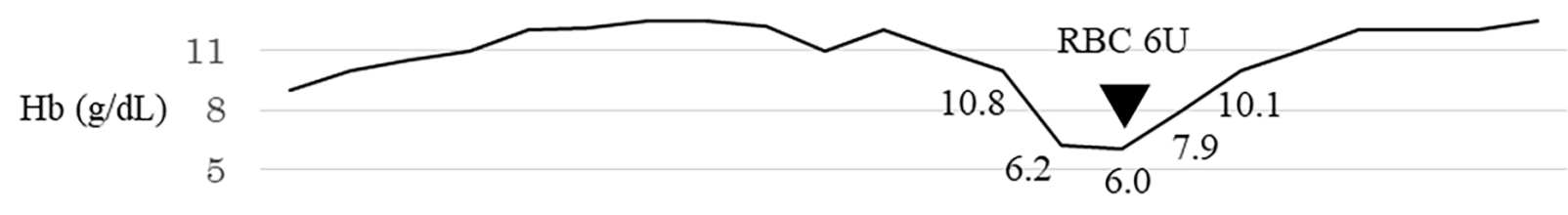

Intravenous cyclophosphamide $500 \mathrm{mg}$

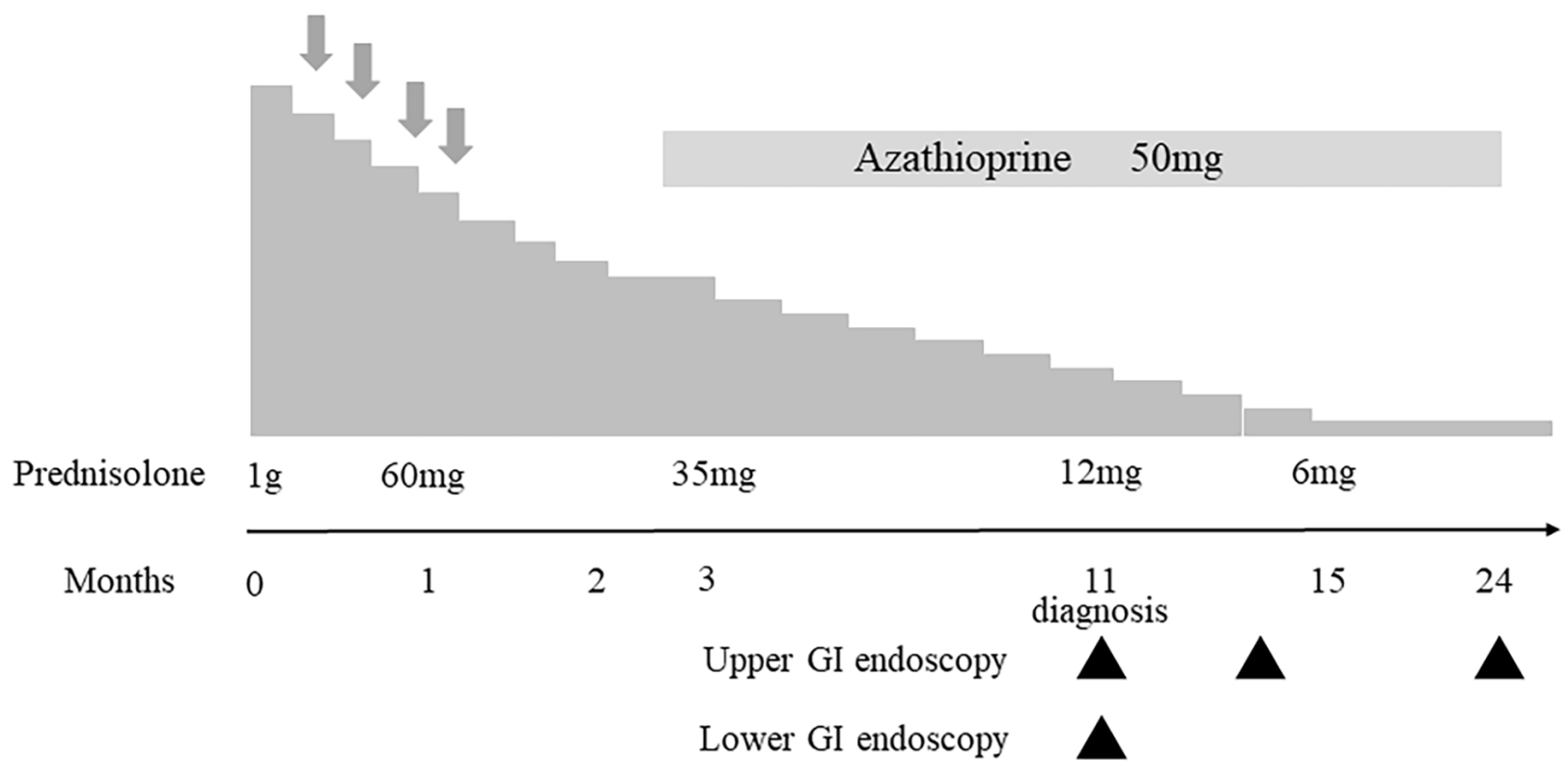

Figure 1. The clinical course with medication history.

Upper and lower GI endoscopy showed multiple brightreddish protruding lesions with ulcers (Fig. 2). We found a total of 10 lesions in the stomach and 16 in the colon. No active bleeding was observed from any of the lesions. A biopsy of the lesions revealed the presence of proliferating spindle cells with vascular channels filled with blood cells on Hematoxylin and Eosin (H\&E) staining (Fig. 3A). Immunohistochemical staining revealed the expression of the lymphatic vessel endothelial cell marker D2-40 (Fig. 3B) and the blood vessel endothelial cell marker CD34 (Fig. 3C). Some endothelial cells were also positive for HHV-8 LANA-1 (Fig. 3D).

A diagnosis of GI-KS was made based on the endoscopic and pathological findings. We considered that the development of GI-KS was associated with immunosuppression induced by steroid use and initiated treatment by withdrawal of prednisolone. Over the next 4 months, prednisolone was tapered to $6 \mathrm{mg} / \mathrm{day}$. At five months after the diagnosis of GI-KS, repeat upper GI endoscopy showed that the ulcers and reddish lesions had become smaller, and marked improvement was noted after 13 months (Fig. 4). No clinical recurrence occurred during two years of follow-up.

\section{Discussion}

We identified several important clinical features in the present case. First, GI-KS can occur in isolation. KS mani- fests primarily as a cutaneous disorder, with visceral involvement (4). Nagata et al. reported that $75.8 \%$ of AIDSassociated GI-KS patient had cutaneous KS (5). Iatrogenic GI-KS without cutaneous lesions is considered rare. Second, GI-KS lesions were found in the esophagus, colon, and rectum, which was consistent with findings from a previous study $(5,6)$. Nagata et al. reported that GI-KS involvement was frequently found in the stomach, duodenum, colon, esophagus, and rectum, in order of increasing frequency (5), whereas Viazis et al. reported that GI-KS involvement was rarely found in the small intestine (6). We did not perform small intestinal endoscopy due to the invasiveness of the procedure and because an examination of the small intestine would not have altered the management or treatment in this case. Third, previous studies have shown distinctive endoscopic findings of GI-KS, such as reddish patches, a polypoid appearance, submucosal tumor-like lesions, and ulcerative submucosal tumor (7), which were detected in our case and facilitated the diagnosis. Fourth, a biopsy of the stomach revealed the presence of proliferating spindle cells with vascular channels filled with red blood cells on H\&E staining (Fig. 3A), which is pathologically characteristic of KS (8). This is seen as reddish mucosa on endoscopy (Fig. 2). We believe that the abundance of red blood cells indicated a small amount of continuous bleeding, which in turn led to the severe anemia. Fifth, GI-KS was induced by steroid use, which is a particularly important feature of this 

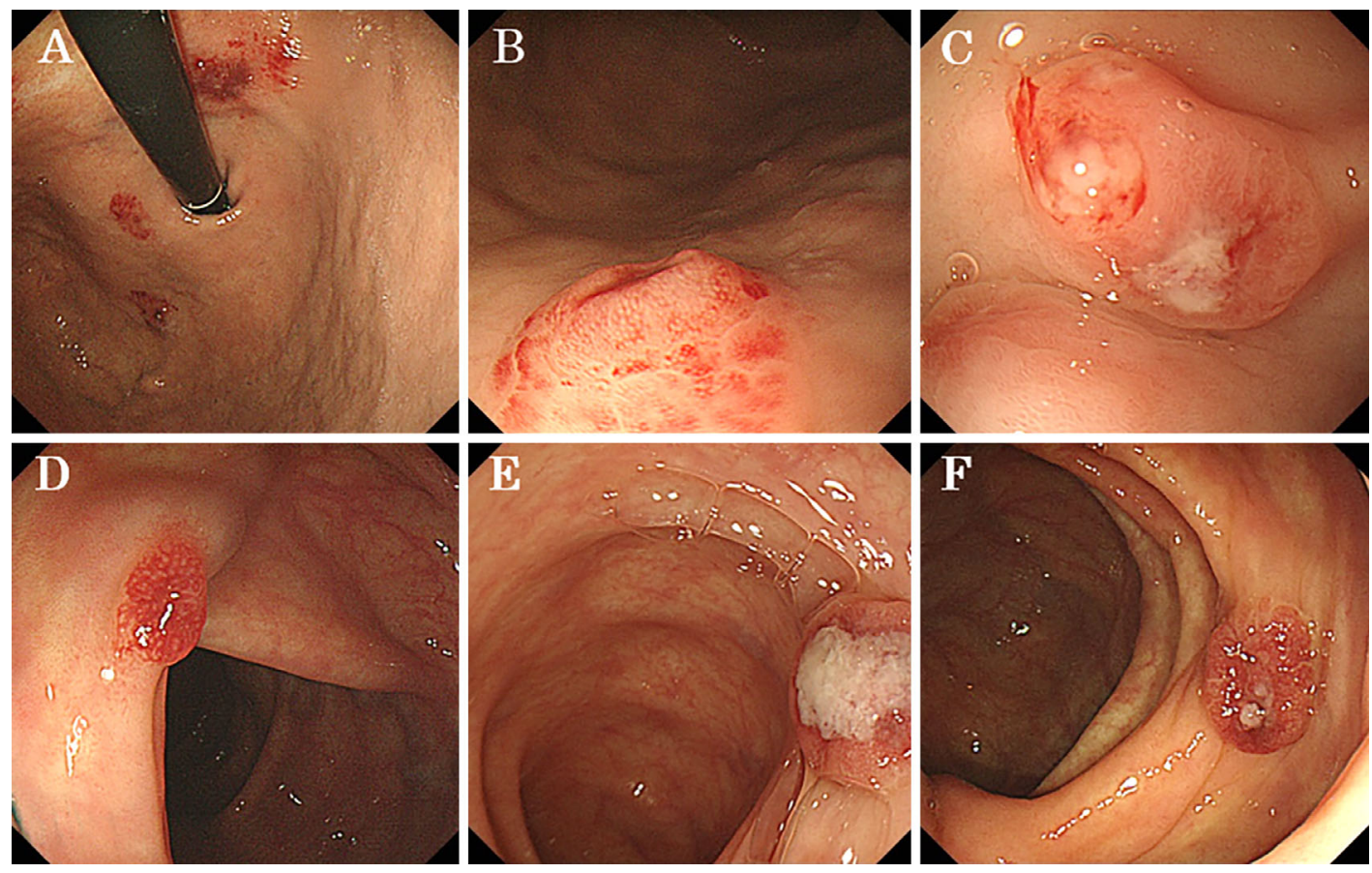

Figure 2. Endoscopic findings of upper and lower GI tract. A: Multiple reddish, flat lesions in the upper body of the stomach. B: Submucosal tumor-like lesion in the lower body of the stomach. C: Submucosal tumor-like lesion with ulceration in the antrum of the stomach. D: Reddish polypoid lesion in the descending colon. E: Submucosal tumor-like lesion with central ulcer in the sigmoid colon. F: Reddish submucosal tumor-like lesion in the ascending colon.

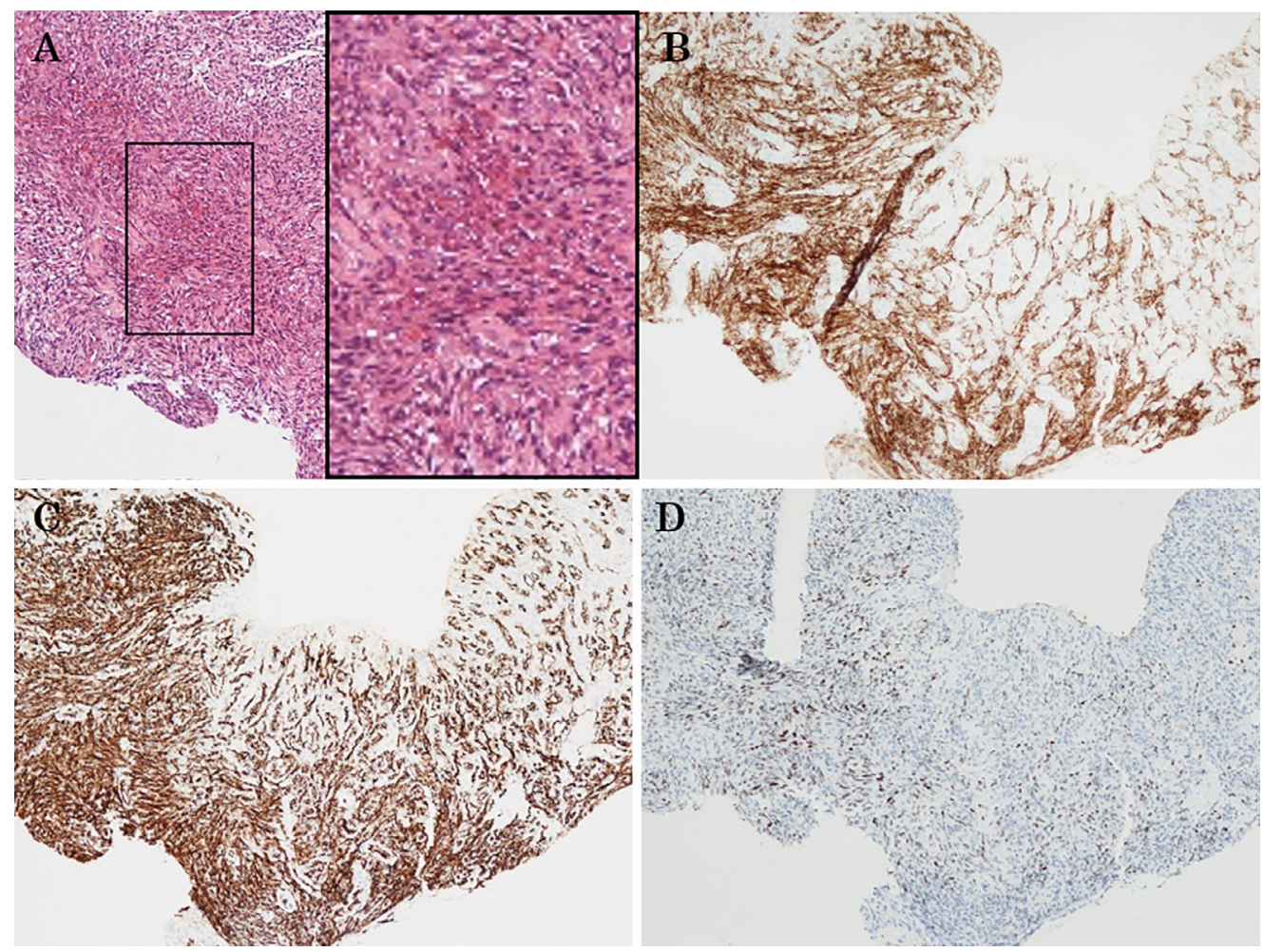

Figure 3. Histological findings of the biopsy specimen from the stomach. A: Low-power view showing a distinct proliferative lesion on Hematoxylin and Eosin staining and high-power view showing spindle cell proliferation with vascular channel formations filled with blood cells $(\times 100, \times 200)$. C: The vascular gaps are lined with endothelial cells when stained with D2-40 ( $\times 100)$. D: The vascular gaps are lined with endothelial cells when stained with $\mathrm{CD34}(\times 100)$. E: Some endothelial cells are positive for HHV-8 ( $\times 100)$. 


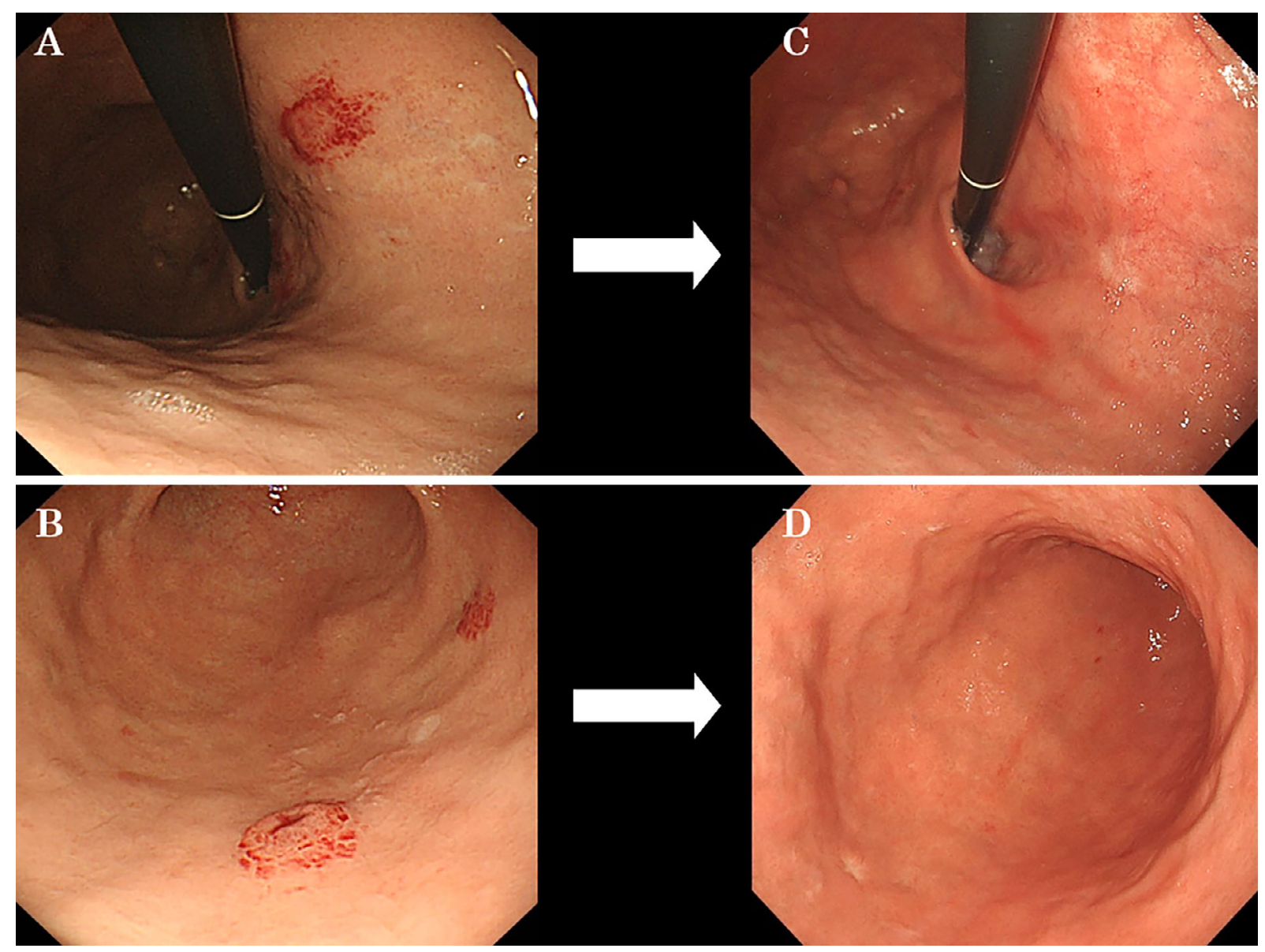

Figure 4. Changes in upper gastrointestinal endoscopic findings after treatment. A: Reddish flat lesions in the upper body of the stomach. B: Submucosal tumor (SMT) -like lesion in the lower body of the stomach. C: Gastric mucosa in the upper body of the stomach at 13 months after the diagnosis. D: Gastric mucosa in the lower body of the stomach at 13 months after the diagnosis.

case.

The characteristics, management, and prognosis of patients with steroid-induced KS remain unknown; thus, we reviewed the English-language literature in the MEDLINE database by searching with keywords "Kaposi's sarcoma", "steroid", and "immunosuppression". We excluded HIVpositive patients and post-transplantation patients and eventually identified 33 cases of iatrogenic KS due to systemic corticosteroid use (22 men, 11 women; mean age 56 years old, range 7-84 years old) (Table) (9-41). The underlying diseases included autoimmune disorders such as pemphigus vulgaris, bullous pemphigoid, rheumatoid arthritis, Behçet's disease, ulcerative colitis, and Crohn's disease. KS most frequently developed on the skin in 26 cases, followed by the GI tract in 11 cases. Of the 11 GI cases, isolated GI-KS accounted for 6 cases, all of which had ulcerative colitis or Crohn's disease. The most commonly used steroid was prednisolone, and the amount of steroid used ranged from 2.5 to $80 \mathrm{mg} /$ day. In 20 of 33 cases, discontinuation or tapering of the steroid dose was selected for treatment. Of these 20 cases, $14(70 \%)$ showed improvement, while 6 (30\%) did not. In our case, isolated GI-KS was induced by prednisolone that was being administered for the treatment of granu- lomatosis with polyangiitis. This is the first case of isolated GI-KS without inflammatory bowel disease. GI-KS was improved by tapering prednisolone to $6 \mathrm{mg} / \mathrm{day}$.

In conclusion, KS can be seen in long-term steroid users even in the absence of HIV infection or transplantation. Steroids are the most widely used form of immunosuppressive therapy, and caution should be practiced in order to prevent the development of $\mathrm{KS}$ as an opportunistic infection. When patients on long-term steroid therapy present with overt GI bleeding and anemia, endoscopy with a biopsy seems to be essential for a definitive diagnosis.

The authors state that they have no Conflict of Interest (COI).

\section{Financial Support}

This study was supported, in part, by Grants-in-Aid for Research from the National Center for Global Health and Medicine (29-1017), and Grant-in-Aid for research on HIV/AIDS from the Health, Labour and Welfare Science Research Grants of Japan (19HB1003). 
Table. Summary of 33 Cases of Steroid-induced Kaposi's Sarcoma.

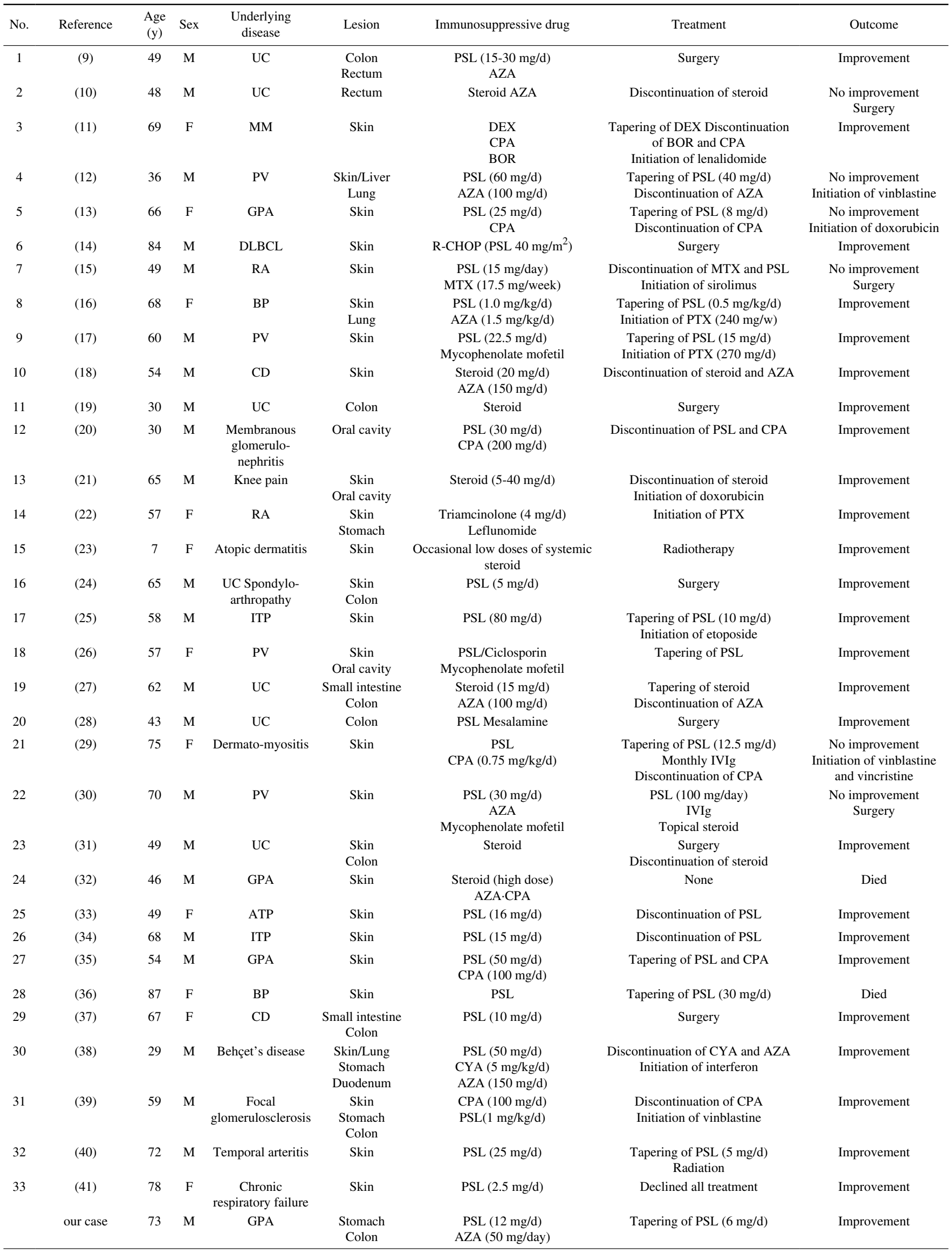

ATP: autoimmune thrombocytopenic purpura, AZA: azathioprine, BOR: bortezomib, BP: bullous pemphigoid, CD: Crohn's disease, CPA: cyclophosphamide, CYA: cyclosporin, DEX: dexamethasone, DLBCL: diffuse large B-cell lymphoma, GPA: granulomatosis with polyangiitis, IVIg: intravenous immunoglobulin, ITP: idiopathic thrombocytopenic purpura, MM: multiple myeloma, MTX: methotrexate, PSL: prednisolone, PTX: paclitaxel, PV: pemphigus vulgaris, RA: rheumatoid arthritis, UC: ulcerative colitis 


\section{References}

1. Antman K, Chang Y. Kaposi's sarcoma. N Engl J Med 342: 10271038, 2000.

2. Martin RW 3rd, Hood AF, Farmer ER. Kaposi sarcoma. Medicine (Baltimore) 72: 245-261, 1993.

3. Thompson GB, Pemberton JH, Morris S, et al. Kaposi's sarcoma of the colon in a young HIV-negative man with chronic ulcerative colitis. Report of a case. Dis Colon Rectum 32: 73-76, 1989.

4. Dezube BJ. Clinical presentation and natural history of AIDSrelated Kaposi's sarcoma. Hematol Oncol Clin North Am 10: 1023-1029, 1996.

5. Nagata N, Shimbo T, Yazaki H, et al. Predictive clinical factors in the diagnosis of gastrointestinal Kaposi's sarcoma and its endoscopic severity. PLoS One 7: e46967, 2012.

6. Viazis N, Vlachogiannakos J, Georgiadis D, Rodias M, Noutsis C, Karamanolis DG. Classic Kaposi's sarcoma and involvement of the small intestine as shown by capsule endoscopy. Endoscopy $\mathbf{4 0}$ (Suppl 2): E209, 2008.

7. Nagata N, Igari T, Shimbo T, et al. Diagnostic value of endothelial markers and HHV-8 staining in gastrointestinal Kaposi sarcoma and its difference in endoscopic tumor staging. World J Gastroenterol 19: 3608-3614, 2013.

8. Nagata N, Sekine K, Igari T, et al. False-negative results of endoscopic biopsy in the diagnosis of gastrointestinal Kaposi's sarcoma in HIV-infected patients. Patholog Res Int 2012: 854146, 2012.

9. Shah N, Lidofsky S, Laskiewicz L. Colorectal Kaposi sarcoma in an immunosuppressed ulcerative colitis patient. J Gastrointest Surg 22: 1301-1302, 2018

10. Duh E, Fine S. Human herpesvirus-8 positive iatrogenic Kaposi's sarcoma in the setting of refractory ulcerative colitis. World J Clin Cases 5: 423-427, 2017.

11. Chavarot N, Lebbe C, Thervet E, Bouscary D, Karras A. Bortezomib does not prevent the occurrence of Kaposi's sarcoma in patients with haematological malignancies: two case reports. Acta Derm Venereol 97: 1138-1139, 2017.

12. Cohen-Barak E, Sonnenscien D, Ziv M, Shani-Adir A, Rozenman D. Kaposi's sarcoma in a patient with pemphigus vulgaris. Int J Dermatol 55: 85-88, 2016.

13. Saxena A, Netchiporouk E, Al-Rajaibi R, Billick R, Roshdy O. Iatrogenic Kaposi's sarcoma after immunosuppressive treatment for granulomatosis with polyangiitis (Wegener's). JAAD Case Rep 1: 71-73, 2015.

14. Ureshino $\mathrm{H}$, Ando $\mathrm{T}$, Kojima $\mathrm{K}$, et al. Rituximab-containing chemotherapy (R-CHOP)-induced Kaposi's sarcoma in an HIVnegative patient with diffuse large B cell lymphoma. Intern Med 54: 3205-3208, 2015.

15. Wu W, Li C, Lee RA, Hata T. The use of sirolimus to treat Kaposi's sarcoma in an HIV-negative rheumatoid arthritis patient on disease-modifying drug therapies. Int J Dermatol 54: 1188-1190, 2015.

16. Wang $\mathrm{T}$, Li C, Yang C, et al. Identification of human herpesvirus8 in Kaposi's sarcoma with bullous pemphigoid. Chin Med J (Engl) 127: 786-788, 2014.

17. Balighi K, Daneshpazhooh M, Aghazadeh N, et al. Pemphigus vulgaris-associated Kaposi's sarcoma: response to paclitaxel and review of the literature. J Eur Acad Dermatol Venereol 28: 987994, 2014.

18. Kilincalp S, Akinci H, Hamamci M, Coskun Y, Yuksel I. Kaposi’s sarcoma developing in a HIV-negative Crohn's disease patient shortly after azathioprine and corticosteroid treatment. J Crohns Colitis 8: 558-559, 2014

19. Hamzaoui L, Kilani H, Bouassida M, et al. Iatrogenic colorectal Kaposi sarcoma complicating a refractory ulcerative colitis in a human immunodeficiency negative-virus patient. Pan Afr Med J 15: 154, 2013.
20. Al-Brahim N, Zaki AH, El-Merhi K, Ahmad MS. Tonsillar Kaposi sarcoma in a patient with membranous glomerulonephritis on immunosuppressive therapy. Ear Nose Throat J 92: E1-E4, 2013.

21. Wani GM, Ahmad SM, Qayoom S, Khursheed B, Khan AR. Corticosteroid induced, HHV-8 positive Kaposi's sarcoma in a nonHIV elderly patient. J IMA 44: 2012.

22. Lee SY, Jo YM, Chung WT, Lee SW, et al. Disseminated cutaneous and visceral Kaposi sarcoma in a woman with rheumatoid arthritis receiving leflunomide. Rheumatol Int 32: 1065-1068, 2012.

23. Salem HA, El Sohafy M, Abd El Gawad M. Kaposi's sarcoma in an atopic dermatitis patient: a case report and a review of literature. Pediatr Dermatol 28: 547-549, 2011.

24. Rodriguez-Pelaez M, Fernandez-Garcia MS, Gutierrez-Corral N, et al. Kaposi's sarcoma: an opportunistic infection by human herpesvirus-8 in ulcerative colitis. J Crohns Colitis 4: 586-590, 2010.

25. Choi KH, Byun JH, Lee JY, Cho BK, Park HJ. Kaposi sarcoma after corticosteroid therapy for idiopathic thrombocytopenic purpura. Ann Dermatol 21: 297-299, 2009.

26. Serdaroglu S, Antonov M, Demirkesen C, Tuzun Y. Iatrogenic Kaposi's sarcoma in a patient with pemphigus vulgaris. Clin Exp Dermatol 34: 839-840, 2009.

27. Svrcek M, Tiret E, Bennis M, Guyot P, Flejou JF. KSHV/HHV8associated intestinal Kaposi's sarcoma in patient with ulcerative colitis receiving immunosuppressive drugs: report of a case. Dis Colon Rectum 52: 154-158, 2009.

28. Girelli CM, Serio G, Rocca E, Rocca F. Refractory ulcerative colitis and iatrogenic colorectal Kaposi's sarcoma. Dig Liver Dis 41: 170-174, 2009.

29. Simeoni S, Puccetti A, Moruzzi S, Tinazzi E, Peterlana D, Lunardi C. Dermatomyositis complicated with Kaposi sarcoma: a case report. Clin Rheumatol 26: 440-442, 2007.

30. Avalos-Peralta P, Herrera A, Rios-Martin JJ, Perez-Bernal AM, Moreno-Ramirez D, Camacho F. Localized Kaposi's sarcoma in a patient with pemphigus vulgaris. J Eur Acad Dermatol Venereol 20: 79-83, 2006.

31. Bursics A, Morvay K, Abraham K, et al. HHV-8 positive, HIV negative disseminated Kaposi's sarcoma complicating steroid dependent ulcerative colitis: a successfully treated case. Gut 54: 1049-1050, 2005.

32. Hoff M, Rodevand E. Development of multiple malignancies after immunosuppression in a patient with Wegener's granulomatosis. Rheumatol Int 25: 238-240, 2005.

33. Monti M, Mancini LL, Ceriani R, Hendrickx I, Guizzardi M. Iatrogenic Kaposi's sarcoma and HCV infection. J Eur Acad Dermatol Venereol 18: 191-193, 2004.

34. Toyohama T, Nagasaki A, Miyagi J, et al. Kaposi's sarcoma in a human immunodeficiency virus-negative patient treated with corticosteroid for idiopathic thrombocytopenic purpura. Intern Med 42: 448-449, 2003.

35. Deschenes I, Dion L, Beauchesne C, de Brum-Fernandes A. Kaposi's sarcoma following immune suppressive therapy for Wegener's granulomatosis. J Rheumatol 30: 622-624, 2003.

36. Sato-Matsumura KC, Matsumura T, Nabeshima M, Katano H, Sata T, Koizumi H. Serological and immunohistochemical detection of human herpesvirus 8 in Kaposi's sarcoma after immunosuppressive therapy for bullous pemphigoid. Br J Dermatol 145: 633-637, 2001.

37. Cohen RL, Tepper RE, Urmacher C, Katz S. Kaposi's sarcoma and cytomegaloviral ileocolitis complicating long-standing Crohn's disease in an HIV-negative patient. Am J Gastroenterol 96: 30283031, 2001.

38. Kotter I, Aepinus C, Graepler F, et al. HHV8 associated Kaposi's sarcoma during triple immunosuppressive treatment with cyclosporin A, azathioprine, and prednisolone for ocular Behçet's disease and complete remission of both disorders with interferon 
alpha. Ann Rheum Dis 60: 83-86, 2001.

39. Zerbi S, Saruggia M, Brambilla L, Lodeville D, Buccianti G. Kaposi's sarcoma in a patient with focal glomerulosclerosis. J Nephrol 14: 299-303, 2001.

40. Kroumpouzos G, Delaney T, Phillips TJ. Combined classic and iatrogenic Kaposi's sarcoma. Corticosteroid withdrawal can result in remission. Postgrad Med 108: 103-106, 2000.

41. Kondo $Y$, Izumi $T$, Yanagawa $T$, Kanda $H$, Katano $H$, Sata $T$.
Spontaneously regressed Kaposi's sarcoma and human herpesvirus 8 infection in a human immunodeficiency virus-negative patient. Pathol Int 50: 340-346, 2000

The Internal Medicine is an Open Access journal distributed under the Creative Commons Attribution-NonCommercial-NoDerivatives 4.0 International License. To view the details of this license, please visit (https://creativecommons.org/licenses/ by-nc-nd/4.0/).

(C) 2020 The Japanese Society of Internal Medicine Intern Med 59: 625-631, 2020 